\title{
Issues Existing in the Capital Market in Jilin Province and Solutions
}

\author{
Hong Li \\ School of Law, Changchun University of Science and Technology \\ No. 7989 Weixing Road, Changchun 130022, China \\ E-mail:1h8879@163.com
}

Received: January 4, 2012

Accepted: January 17, 2012 Published: March 1, 2012

doi:10.5539/jpl.v5n1p196

URL: http://dx.doi.org/10.5539/jpl.v5n1p196

\begin{abstract}
Development of the capital market has attracted external sources of finance to the great extent, promoted Jilin Province to change from an old industrial base to an advanced international manufacturing base and greatly enhanced the overall economic strength of Jilin Province. Nonetheless, considering the current situation, mobility of capital in economy of Jilin Province is not yet strong and insufficient capital is still an impediment to constrain economic and social development of Jilin Province. Through a survey and analysis of the development condition of capital market in Jilin Province, this article expounds the major problems existing in development of capital market in Jilin Province and puts forward solutions for development of capital market in Jilin Province.
\end{abstract}

Keywords: Capital market, Issues, Solutions

\section{Introduction}

Capital market refers to an occasion for security financing and borrowing and lending of capital and dealing in securities which have been operated for at least one year, which is also termed as a market for medium to long term funds. As the platform for resource allocation and the engine for regional economy, capital market is of great significance to guide flow direction of resources and promote adjustment of economic structure and it is directly related with the overall situation of the national economy and regional development. It mainly has three functions in economic development. The first one is the fund accommodation function. The capital market is constituted by multiple financial products. The two parties of supply and demand resort to the policy of the Central Bank and decide the price of the financial products by the market competition law so as to set up a bridge for financing of capital of the two parties. The second one is the property right function, namely, the function to constrain the property right of market subjects and serving as an intermediary for property rights exchange. It plays an important role in the process of re-organization of property rights of an enterprise by reforming the managerial mechanism of an enterprise, providing capital financing for an enterprise, conveying property rights exchange information and offering intermediary service of property rights. The third one is the allocation function. The capital market plays a directing role in resource allocation by means of directing the flow direction of capital and realizes resource optimization and allocation by making use of the evaluation, selection and supervision mechanism of the capital market. Worldwide experiences indicate that, in the modern market economy situation, direct financing is an effective means to effectively convert social savings fund into long term investment and promote enterprise capital formation and sustainable growth of economy.

In the past few years, propelled by the capital market, economy in Jilin Province has been developed rapidly. So far, there has been 36 listed companies in Jilin Province which have collected more than 30 billion RMB Yuan of external sources of funds, which has greatly boosted industrial development in Jilin Province. However, considering the current situation, capital insufficiency is still an issue existing in economic and social development in Jilin Province. According to the survey data, among external sources of funds in enterprises all over the country in 2010, bank credit accounted for $86.3 \%$ and stocks and corporate bonds accounted for $13.7 \%$, while the bank credit in Jilin Province accounted for $97.8 \%$ and corporate bonds and stocks merely accounted for $2.2 \%$, with an obvious low proportion of financing by the capital market. The formally initiated Growth Enterprise Market has had approximately 30 listed companies, without even one company in Jilin Province. The following problems generally exist in the capital market in Jilin Province: low securitization rate, inactive capital market, bad quality of some listed companies, low capacity of financing and re-financing and few financing channels, etc.

Yet, we ought to notice that the capital market in Jilin Province is simultaneously faced up with a benign opportunity. 
Since the economic extroversion in Jilin Province is low, the international financial crisis has caused little impacts on Jilin Province. In adjustment of economic structure, Jilin Province has the comparative advantage of undertaking industrial transfer. Given the macro policy of the country, the country continues to carry out the strategy of revitalizing the old Northeast Industrial Bases and approves constructing Changjitu Development and Opening-up Pilot Area, which all have provided a benign opportunity for development of the capital market in Jilin Province.

Hence, how to grab this brand-new historical opportunity and set up a regional capital market that has a perfect system and reasonable structure and is able to adapt to economic development need of Jilin Province is a problem that needs to be urgently resolved for economic and social development of Jilin Province.

\section{An Analysis of the Status Quo of Capital Market Development in Jilin Province}

The earliest rudiment of capital market in Jilin Province can track back to as early as in 1988, when some futures information consulting institutes and joint-stock system companies appeared one after another in Jilin Province. Jilin Security Company was officially set up in July 1988. In 1991, Jilin Security Company began to formally take over share dealing as an agent of Shanghai Stock Exchange. In 1993, the first listed company in Jilin Province, Northeast Hualian was listed on the stock market of Shanghai Stock Exchange. In 1993, Jilin Commission for Structural Reforms, Jilin Government Research Center and Jilin Department of Grain completed successively re-organization of Changchun Commodity Exchange and Changchun Cereals and Edible Oils Exchange, put them into operation and organized futures dealing of cereals and edible oils. This formed the basic framework for futures market in Jilin Province and symbolized that securities and futures industry and the market network in Jilin Province had taken the shape.

Ever since 1993 when the first listed company was listed on the stock market in Jilin Province and after development for almost twenty years, the capital market in Jilin Province has begun to take its shape and its functions are gradually improved. A large number of large scale state-owned enterprises and leading industrial enterprises came into the market successfully, which promoted adjustment of industry and products structure and drove development of the whole industry. By the end of 2010, there had already been 36 listed companies in Jilin Province, with a total capital stock amount of 14.9 billion RMB Yuan and a total market capitalization of approximately 100 billion RMB Yuan, which almost accounted for 40\% of GDP in Jilin Province. Development of the capital market has propelled economy in Jilin to develop continuously. Even in 2009 when the whole world was encountered with the financial crisis, the growth of GDP in Jilin Province still remained at the level of 12.2\%, ranking the first three in the whole country. In terms of attracting external sources of funds, actual disbursement of foreign capital in Jilin Province increased by $18.7 \%$ compared with the same period in the previous year and funds of other provinces that were brought into Jilin increased by 35.6\% compared with the same period in the previous year. By the end of 2010, there had been 63 countries and regions that made an investment in Jilin Province. At the same year, 196 foreign-owned enterprises were newly added and the cumulative foreign-owned enterprises were 2311, including 49 Top 500 global enterprises and also a great number of well known enterprises at home that were settled down in Jilin Province one after another. These external enterprise investment involves auto parts, petrochemical industry, agricultural products processing, service and so on, having enormous economic potential.

At the time when we fully affirm these achievements, we should simultaneously notice that, since the major motive power for economic growth of Jilin Province mainly comes from investment and the scale growth mainly depends on such labor intensive industries as energy development and manufacturing industry, etc., as well as such resource industries as food and minerals, etc., the mobility of capital in economy in Jilin Province is still not strong and the financial leverage and the pushing effect of the capital market have been far from getting fully played.

\section{Major Issues Existing in the Capital Market in Jilin Province}

\subsection{Small Number of Listed Companies and Weak Strength of the Listed Companies}

Jilin Province has preliminarily formed a relatively complete listed company system that has a great scale, which has played its due role in regional economic and social development. Nevertheless, compared with development of listed companies in a nationwide scope, the system still has huge gap both in terms of quantity and in terms of quality. By the year 2010, there had been 36 A-shares listed companies, 2 security companies, 59 stock exalters, 6 futures companies, 1 overseas futures business certificate holding enterprises and 10 sales departments in Jilin Province. The amount of listed companies in Jilin Province accounted for $2.17 \%$ of the total listed companies in the country, the shares outstanding accounted for $0.62 \%$ of the whole country and the total market capitalization merely accounted for $0.82 \%$ of the whole country. Considering cultivation of companies to be listed on the stock market, there are only more than ten enterprises in Jilin Province which are pre-listing tutored at present. In the past three years, there have been only 5 newly listed companies and 6 re-financing companies, with a cumulative financing of 3.27 billion RMB Yuan, which has a large gap compared with coastal developed provinces and cities. 


\subsection{Direct Financing Channels in Medium and Small-Sized Enterprises Are Single}

There is rarely any channel of direct financing for medium and small-sized enterprises in Jilin Province. A-share is seeking financing by large-sized enterprises by being listed on the stock market, and there are no listed enterprises in Jilin Province in B -share and H-share. The bill market and the enterprise bond market are also concentrated in large-sized enterprises, and medium and small-sized enterprises have difficulty in direct financing, which aggravates dependence on indirect financing. Ever since the Growth Enterprise Market was launched, there have been 28 enterprises to take the lead in being listed and trading in the Growth Enterprise Market. For the time being, there have been approximately 200 enterprises all over the country that have submitted to apply for the Growth Enterprise Market, whereas there has even neither been one enterprise in Jilin Province to take the lead nor one that has entered the approval procedure.

\subsection{Development of Local Property Rights Exchange Market Lags behind}

It has not been long ever since Changchun Property Rights Exchange Center in Jilin Province was set up, and its vigor of publicity and reporting is far from enough, so it has not obtained great reputation in the whole province, as a result of which quite a lot of enterprises, especially small and medium sized enterprises have not been able to enter the exchange center for a public and rational trading for their property rights exchange. There are even some enterprises in Jilin Province that go round the sun to meet the moon. They take their property rights to property rights exchange centers in other provinces to be listed for trading, which not only increases the trading costs of the enterprises that transfer their property rights, but also brings a lot of difficulties for delivery of property rights in the future. This indicates that, the function of optimum distribution of resources in the property rights market in Jilin Province has not been fully played and a platform has not been established for stock rights exchange in non-listed companies. It is far from satisfying the financing demands of the vast majority of small and medium sized enterprises and private enterprises in Jilin Province.

\subsection{The Soft Environment for Survival of Enterprises is still Open for Further Improvement}

Due to the one stock dominance of state-owned shares, the government has put too much interference in enterprises and most senior management positions in the enterprises are appointed by the administrative department, which leads to deep consciousness of chief executive and weak market concept among listed companies and securities institutes in Jilin Province. Considering the supervision mechanism, the current situation of too much dependence on administrative supervision can obviously no longer fit in with the requirement of capital market development. As a result of lack of flexibility, the whole quality of the supervision team and the efficiency of the supervision are far from being able to completely adapt to the requirement of capital market development. The administrative idea and the consciousness of enforcement of law among the governmental functional departments are still open for an alteration and the consciousness of service is also open for further improvement.

\section{Solutions to Improve the Capital Market in Jilin Province}

\subsection{To Enhance the Quality of Listed Companies}

Listed companies are a group which has the development superiority in economic operation. And as a leading enterprise and demonstrative enterprise in Jilin Province, listed companies ought to inject new life into the industrial structure adjustment and development of enterprises in Jilin province by means of re-distributing resources through the capital market and leading industrial innovation and industrial upgrading in Jilin Province. On one hand, listed companies should attach great importance to the financing function of capital market, attempt to enhance the corporate performance by integrating resources, retain the financing qualification of allotted shares, give full play to the favorable conditions of advanced mechanism, concentrated capital and continuous financing, take the initiative in selecting a project and establishing a project by taking into consideration of the five major industries, including the traditional industries with comparative advantages, strengthen updating and reformation of technology, continue to develop new products and enable running of capital and industrial operation to form a benign interactive situation by means of refinancing. On the other hand, listed companies should make use of capital running means to integrate resources, realize merger and restructuring, fulfill expansion with low costs and make the companies stronger and larger. It is enough to expand and vigorously develop the current listed companies and to enhance their capacity of profit making to lay a good foundation for the capital market in Jilin Province.

\subsection{To Expand the Quantity of Listed Companies}

According to the development plan of "the Twelfth-Five Year" in Jilin Province, as for those industries that have been listed as key enterprises to be developed, the government should make an overall planning and offer key support to push forward the enterprises to be restructured and listed on the stock market and carry out a working plan to propel the enterprises to be listed. The Acting Governor of Jilin Province, Wang Rulin made a statement 
recently that, Jilin would implement the "project of cultivating enterprises to be listed" and would select a hundred enterprises that were eligibly qualified and carry out training of listing, which will be a vigorous measure for Jilin province to propel development of the capital market. The government at all levels and all departments concerned should make a selection among all enterprises in the province, establish a files tracking system for high-tech and new enterprises and enterprise groups, focus on their development, take the initiative in creating conditions for them to be listed and propel capital construction of the enterprises at an opportune moment. They ought to strengthen relevant training on entrepreneurs, get them familiar with the capital market, resort to the functions of capital market to improve the stock rights ownership structure of the enterprises, establish the system of board of shareholders and the system of board of directors and strengthen internal constraint mechanism within the enterprises. In addition, they should play the leading role of the government in organizing the work of listing, such as, taking the initiative in strengthening connection with the securities supervision department, securities exchange and securities companies to obtain their support and guidance, form one-to-one assistance and support and offer pre-listing tutoring for the enterprises. The listing tutoring instates at all levels should provide whole process guidance on listing of enterprises, analyze problems that generally exist in listing of enterprises together with securities supervision department, put forward solutions and enhance the efficiency of enterprises to apply for being listed and the efficiency of passing the application process.

\subsection{To Vigorously Develop Private Equity Investment Funds}

Private equity investment refers to the equity investment in non-listed enterprises by the means of private investment. After the enterprises are reformed and re-governed, they are promoted by the means of being listed, merger and management buyout, etc. In the past few years, small and medium sized enterprises in Jilin Province have been developed rapidly, and due to their short history and small scale, they have great difficulty in acquiring capital support from the traditional financing channels of bank, etc. How to resolve the problem of capital and break through the bottleneck of management are a common topic that is encountered by quite a huge number of small and medium sized enterprises. As the booster rocket for growth of small and medium sized enterprises, the greatest advantage of private equity funds in small and medium sized enterprises not only lies in that it has provided enough capital support for developing small and medium sized enterprises, but has also furnished one-stop service for the enterprises that are invested in terms of expansion of product market, corporate management, listing of companies and so on, by taking advantages of its own capital conditions and talent conditions. At present, private equity investment is vigorously developed all over the country. Thus, Jilin Province is supposed to strive to gain support of the nation through multiple channels, pay attention to highlighting its own characteristics and set up equity investment funds with its own industrial superiority, such as, corn industry fund, auto industry fund, biological industry fund, and so on.

\subsection{To Set up and Make Perfect Stock Rights Exchange Center}

Stock rights exchange center is the center for integration and price fixing of enterprises, which uses a variety of means to make competitive biding transfer more scientific and standardized, such as, network competitive biding, electronic competitive biding, auction and inviting bids, etc. Changchun Property Rights Exchange Center in Jilin Province should fully play its central role as a provincial property rights transfer agency, positively set up a unified property rights exchange platform in the whole province, a unified market transaction rule and strengthen the market function step by step. It is suggested that to make a multi-industrial integration of property rights exchange center and financial consultant and management consulting, etc., to form an overall equity exchange platform. We can set up an office in all cities, which can not only enhance the trading efficiency of a project and cut down on trading costs, but can also realize information sharing and rational distribution of resources. Expanding the scope of property rights exchange business in Jilin Province can open up risk investment business and investment bank business, etc., widen financing channels, enlarge market irradiation and information collecting and scattering competence and play an important role in setting up a unified system of national property rights exchange market.

\subsection{To Improve Governmental Actions and to Enlarge Supporting Strength of the Government}

The government is supposed to change its function, correctly deal with the relationship between the government and the market and improve the legal and supervision system; further simplify administrative examination and approval and build up market distribution and innovation mechanism; strengthen construction of the supervision team and improve the supervision efficiency; intensify arrangement and improvement of relevant listing policies and promulgate new policies and new measures, etc., in due course to speed up development of the capital market.

To sum up, with development of the market economy, demand on distribution of marketization resources is on a daily increase and the scope and degree of the functions of the capital market in the national economy become also more obvious. In order to revitalize development of old industrial bases in Jilin province, we have to resort to 
advanced financing instruments. Thus, development of the capital market in Jilin Province admits of no delay and is also an important approach to boost economic take-off in Jilin Province.

\section{References}

Qiang, Li \& Wang, Zhicheng. (2010). Finance Law. China University of Political Science and Law Press.

Wang, Guogang. (2006). Survey on Hot Issues in China Capital Market. China Financial Publishing House.

Wang, Jinping. (2009). Study on Functions of Capital Market in Rejuvenating Northeast Old Industrial Bases. Theoretical Investigation. (4).

Wu, Zhipan \& Liu, Yan. (2008). Finance Law. Peking University Press.

Zhao, Zhouhao. (2008). Regional Capital Market Development and Innovation. China Modern Economic Publishing House.

Zhou, Li. (2005). Financial Development and Economic Growth in China. China Renmin University Press Co.

Zou, Dewen. (2006). Multilevel Selection and Innovation of China Capital Market. People's Publishing House. 